\title{
Recommended Measures for Prevention of COVID-19
}

\author{
Saurabh Shinde ${ }^{1}$, Dr. Swaroopa Chakole ${ }^{2}$ \\ ${ }^{1}$ Intern, Dept. of Community Medicine, Jawaharlal Nehru Medical College, DattaMeghe Institute of Medical \\ Sciences (Deemed to be University), Sawangi (Meghe), Wardha-442001, Maharashtra, India \\ ${ }^{2}$ Professor, Dept. of Community Medicine, Jawaharlal Nehru Medical College, DattaMeghe Institute of Medical \\ Sciences (Deemed to be University), Sawangi (Meghe), Wardha-442001, Maharashtra, India \\ Email: ${ }^{1}$ saurabhshinde188@gmail.com, ${ }^{2}$ drswaroopachakole@gmail.com
}

Corresponding author's name and address: Dr. SwaroopaChakole , Department of Community Medicine, Acharya VinobaBhave Rural Hospital, DattaMeghe Institute of Medical Sciences (DU).

Corresponding author's email id: drswaroopachakole@gmail.com

Type of Article: Review

Conflict of Interest: None

Funding: DMIMS

Ethical Approval: IEC, DMIMS, Wardha.

\begin{abstract}
DEC 30, 2020, the WHO articulated the COVID-19 erupt an overall prosperity emergency of overall worry with this during March 2020, began and depict as a pandemic to underline the profundity among the situation with knownevery countries to take an action in distinctive pollution \&preventing transmission. Amazingly, there is no remedy that has been attested by the FDA, experienced controlled examinations and showed an effect on the disease for this overall pandemic. Regardless of the way that there are solutions for ailments and progressions took by hops and cutoff points in our day, the most grounded and best weapon that society has against this contamination that is impacting prosperity just as monetary perspectives, administrative problems, and community solicitation, is the neutralization of its transmitting. An essential worry in hindering the public field transmission is tidiness of hand, public isolating with separation. With extended testing limit, perceiving more patients of COVID-19 positive in the organization will moreover engage the lessening of discretionary patients with stricter disconnect rules.
\end{abstract}

KEYWORDS :-Coronavirus, India, counteraction, Isolate, Social Separating

\section{INTRODUCTION}

In Last few months of 2019 a novel COVID-19, presently assigned SARSCoV-2 was identified as the reason for anintense respiratory sickness in territory of China.(1) The World Health Organization (WHO) assigned an illness COVID-19, that represents COVID-19 sickness 2019. The clinical introduction of 2019-nCoV contamination goes from low to high conditions associated with extreme pneumonia with intense respiratory trouble condition with different organ disappointment, which may bring about demise. Upon entering 2020, the COVID 19 was proclaimed by the Forecast WHO to constitute an overall welfare crisis of global concern, which in
March 2020 began being identified as a pandemic underlining the light of the event and calling on all nations to advance towards the identification of sickness and the expansion of forestry and excess.(2)COVID-19 is spread from one person to other person, through respiratory droplets spread during coughing or sneezing. These droplets enter into lungs via mouth or nose who are close to the COVID person. There are different ways are present for transmission of droplets like fomites which are polluted inhaled and dirty aerosol inhalation. Transmission of SARS-CoV-2 from individuals which are asymptomatic arefounded. In any case, how much this happens stays dark.Tragically, there isn't any drug 
approved by the FDA. Disregarding the way, there are alternatives to disease and enhancements takenfrom hops and cutoff points in our present day, the bestbasic strong thingwhich society has against this contamination that is influencing prosperity just as monetary issues, administrative problems, and community solicitation, is the basic reason for spread. On 7 March 2020, WHO circulated time course, "Answering to arrangeCOVID-19 transmission in community," communicates the COVID-19 from transmittingby the headway of coordination parts in prosperity as same in zones, for instance, transportation, travel, business, record, security and various territories which incorporates the absolute community.Cases are stop by the various ways and techniques of measure for Prevention. Patient should be isolated on primary testing and infection should be control carefully and care which must be clinical can be given to infected person. The primary system to general crowd must washing hand with the help of soap or sanitizer liquid and touching the mouth and face with the hand must be avoid which was come in contact with dirty surrounding. Chance of spreading can be decrease by, each one must clean their hand with water and soap, exercise for respiration control, and stay away from crowd and person who are not well. There are standards and notices to show the rules and regulation for the preventing the spread of COVID and use in different country.(3) Organization which works for health sector made the Digital video and spread in different country for the awareness against the current situation.These flags, appropriated all through different bits of society to make most extraordinary notification the centrality of hand tidiness, made care in public. And Use of sanitizer for hand is rise by the people for the instant hygiene of hand and this help to reduce the transmission of pandemic in different country of the world such as Japan, China and Korea. But in some countries, above given measures are not compulsory which cause the increase in the cases.In community spread, social distance should be maintained and most of the country started the Quarantine to the person from others.

\section{MEASURES THAT CONTAIN:}

1. The School, college, university, and offices are shut down.

2. Reduction in the quantity of guests and restricting the contact between the crowded area or place such as jails.

3. Social Gathering, Small meeting, and making of group are Canceled, restricted and avoided respectively.

4. Compulsory quarantine of society having buildings or local living area

5. Internal or outside boundaries terminations.

In the United States, the CDC refreshed its suggestions toward the beginning of April to encourage people for the use of face mask (natively constructed covers \& handkerchiefs) in the crowed place where social distance is not able to maintain specially during the community spread. People are told not to touch the mouth , nose and eyes during removing the face mask and hand should be wash after removing the mask of the face every time.(4)

Reason behind the wearing face mask is principally to stop discharges and avoid keep spreading by people having asymptomatic disease.CDC additionally emphasizes onface mask proposal and care taker in clinical practice, which ought to be saved for medical facility workers.(5)Society is really focusing on suspected patient or recorded corona at house ought to wear a face mask when single room is shared by more people in 
the house. Social distance is intended to decrease collaborations among individuals in a more extensive network, where people might be irresistible yet have not yet been recognized subsequently not yet disconnected . As illnesses communicated by contact and easily through nasal passage beads require a specific closeness of individuals, social removing of people diminish spreading. community separating is especially important where crowding will be possible and accepted, however as such direct contact between the affected case are more, and limitations set uniquely upon people who know to have been uncovered is viewed as inadequate to forestall further spreading. Models for community removing incorporate conclusion of education institutes or places of business or suspension of public business sectors, and undoing gettogethers. Openly showcases it is hard to keep up community distance, impediment of the individual and empowering internet purchasing can diminish the width of contact. Working environments is additionally one of the reason-hazard zones for corona spreading. Thusly, work from home should be supported. Working environments where home working is beyond the realm of imagination.(6)

Studies shows that directed help irresistibleness of SARS-CoV-2 in the asymptomatic stage; crowdseparating in this way by basic significance of building up authority during pandemic time.

\section{PREVENTION TECHNIQUE}

Isolation is most established, best devices for controlling transferable infection episodes. The general wellbeing daily routinewere utilized broadly during 14th century in Italy, boats showing up at the port named Venicewhich affected from plague-contaminated place needed to secure \& hang tight up to forty days preceding landing these enduring travelers. Isolated people were having limitation for exercises in partition of people those are not sick; rather those have been presented to an irresistible specialist or infection, along with target for observing their indications \& guaranteeing very first recognition for the patient. Isolate is not the same as detachment, which is the partition of sick or tainted people from others to forestall the spread of disease or pollution. Taking a gander at the accessible examinations in the writing, isolate is the best technique in diminishing both the quantity of tainted and dead. This is considerably rise compelling in countries where isolation has been started from the first sever patient in the country. Cochrane Library published article assessingtwenty-nine examinations, outcomes demonstrated are isolate could diminish quantity of contaminated at rates from eighty one percent to forty four percent, and quantity of demise from sixty-one to thirty one percent.(7)

The numerical project performedon transmission of Covid-19 in the country named Italy, it was indicated in the absence severe isolate rules the pandemic couldn't be managedand the quantity for auxiliary patient expanded in relation to the size of families. As per reenactment, those family unit who involved 2 individuals with complete isolation set up, more likely auxiliarypatients are three inside the fourteen days-time frames; if family is of six, then increments to 16 . Notwithstanding over eight weekscompleting after the revelation the main patients in the country named US , they informed to remain at house and informed in thirty-three states and by numerous nearby institutes govern by governments were deficient. Then again, while it was enormously condemned, the isolate and serious standards given from China's focal ruling party of the country for each person on the Wuhan nation implied that they had the option to successfully managed quantity of patient nation outside the Hubei state and death rate was decrease.(8) 
WHO suggests that contacts of patients with research center affirmed CORONA be isolated for fourteen days from the last time they were in contact with the patient.(9)

1. Having contact directly with patient having a COVID-19 with less than 1 meter $\&$ for more than fifteen minutes

2. Giving direct consideration for covid-19 patients illness not withutilizing appropriate individual defensive hardware

3. Staying in a similar close climate as a COVID-19 patient (counting sharing a work environment, study hall or family or being at a similar social occasion) for any measure of duration,

4. Traveling in the vicinity of place (which is, less than $1 \mathrm{~m}$ detachment from) a patient having COVID-19 indifferent sort of transport.

Dynamic checking for individuals which are isolated is best and important technique for the managing the covid-19 pandemic in the public area. Presence of less and few compulsory mobile applications which are used for the know and separate the person from isolated person, for example, Japan(10), Korea and China. Country named Turkey, where isolated persons are informed immediately by the help of Mobile Application when the leave the place which was given to live or when they crosse the restricted area. Unquestionably, obstruction charges will likewise expand consistence among isolate. (11)

\section{CLEANSING AND CLEANING}

More prone-contact regions, for example, bedside tables and entryway handles ought to be sanitized daily and customary family unit disinfectant containing a weakened blanch arrangement (one-section dye to ninety-nine sections fluid called water). Area that is not able to clean by Dye seventy percent alcohol which must contain ethanol must be used. Latrines \& washrooms ought to be sanitized and cleanedby weakened dye arrangement (1 section fade to nine sections fluid called water for the preparations of $0.5 \%$ sodium hypochlorite arrangement).(12) Dispensable hand gloves ought to utilize while cleaning, taking care of area, dress, material ruined withliquids in the body. Every pre-owned dispensable debased thing ought to be put in a fixed compartment prior to discarding them with other family unit squander. Garments, bed cloths, and shower and hand towels should clean utilizing standard clothing cleanser. Rubber gloves ought to be used while cleaning or taking care of surfaces, dress, or material dirtied with body liquids. All pre-owned dispensable polluted things ought to be set in a fixed holder prior to discarding them with other family squander.(13)

\section{INDIA AND PREVENTION}

In India, which acted rapidly to control gratis and broad people testing for COVID-19, "pass through testing" was started unexpectedly. Comparable applications dependent on this model are being initiated in country named Germany and different nations after Korea(South). Indian government implemented few measures to control the pandemic. These included physical separating, travel limitations on guests showing up from more prone regions, isolate for country people getting back from more risk areas, $\&$ conclusion of schools\& specific sorts of working environments. The public authority announced at February that all schools, colleges, university including workplaces were to be shut beginning from march.India set up a few measures to restrict development of individuals. Residents 65 years of age or more seasoned, patients with invulnerable framework lack, ongoing lung illness, asthma, COPD, persistent cardiovascular 
infection, constant renal sickness, hypertension, persistent liver illness just as clients of medications that disturb the insusceptible framework were confined from leaving their homes and utilizing community vehicle.(14)All services distributed proper directions on COVID19 avoidance and responsible measures in their association. 40000 lab tests have been taken each day with an aggregate of 72 approved labs, and the quantity of performed day by day tests is continuously expanding. Our outcomes recommend that data dispersal about COVID-19, which causes singular reception of handwashing, cover wearing, and social removing, can be a compelling system to moderate and postpone the pestilence. Early started momentary government-forced social separating can purchase time for medical services frameworks to plan for an expanding COVID-19 weight. We stress the significance of sickness mindfulness in controlling the progressing pandemic and suggest that, notwithstanding strategies on social removing, governments and general wellbeing foundations prepare individuals to receive deliberate measures with demonstrated adequacy to effectively handle COVID-19.

\section{THINGS WHICH ARE RESTRICTED}

In spite of the fact that being solid and steady, the pandemic is a cycle that requirements quick activities and brings out difficulties for all nations. The difficulties experienced in our nation are not more than those accomplished by numerous nations on the planet. We started monitorization of the infection in the early period; likewise, measures were taken early, and the passageway of the illness in our nation was postponed(15-17). A large portion of the arrangements were finished during this period. Having adequate medical clinic beds and emergency unit for practically the entirety of our regions was assessed as a bit of leeway. Furthermore, individual defensive gear, for example, gloves, clinical and respiratory covers, outfits, goggles/face defenders are created in our nation. In this manner, brevity of PPE has not happened, and help has been given to a few nations. Measures have been taken with alert to guarantee that flight limitations and the measures taken at line intersections don't influence worldwide relations. Concerning pandemic, the improvements around the globe and in our nation were observed continuously, and updates with respect to the applications were executed and declared quickly. The pandemic has been reacted by the most reasonable measures for the circumstance in our nation(18-20). To begin with, safeguards were taken to keep the sickness from entering the nation. After the infection was found in our nation, activities were done to forestall and treat the spread of the sickness. As per the pandemic arrangement, activities have been completed with a multi-sectoral approach, and preventive measures have been actualized to cover the general public all in all (21-23). Aftereffects of our study show that there are significant contrasts in the Serbian public's view of dangers introduced by pandemic Novel Coronavirus 2019 especially their overall information opposite the overall danger that novel COVID-19 2019 presents to both themselves and the network everywhere, hazard discernment, hazard the board and prescribed preventive measures to take to diminish the chance of getting sick or kicking the bucket from COVID-19 (24-25). The investigation portrayed in this paper tends to basic introductory strides during the time spent neighborhood and public groundwork for a pandemic sickness calamity. We energize crisis the board organizations in Serbia to utilize the distinctions in open view of dangers recognized in our examination to create upgraded hostile to pandemic sickness readiness measures by advancement of conduct changes that go inseparably with the of selection of 
improved danger the executive's dynamic systems.

\section{CONCLUSION}

All urban communities and towns in Serbiarequire to have debacle ideasthat are custom-made to control situations and areas, not biased summed up plans. Air plane INCIDENCES, disasters, and far-off mass travel mishaps are on the whole totally different from those brought about by dangerous irresistible microorganisms, for example, corona and affecting others. Inside changes should be lenient and upheld. Emergency is kept Infrontof eyes and all the more unmistakably. Future exploration would profit by a more epidemiological methodology (e.g., casecontrol and accomplice consider) to recognize hazard factors for helpless network reactions to transmittable sickness catastrophes, for example, scourges, "prior and then afterward" contemplates taking a gander at a populace in Serbia that has been influenced by irresistible illness calamities, for example, COVID-19 pandemics, and studies utilizing at present approved displaying and recreation strategies.

\section{REFERENCE}

[1] DushyantBawiskar, Pratik Phansopkar, Ayurva Vilas Gotmare. COVID-19 Facets: Pandemics, Curse and Humanity. ijrps. 2020 Aug 6;11(SPL1):385-90.

[2] Clinical Characteristics of Coronavirus Disease 2019 in China | NEJM [Internet]. [cited 2021 Jan 16]. Available from: https://www.nejm.org/doi/full/10.105 6/NEJMoa2002032

[3] Wei WE. Presymptomatic Transmission of SARS-CoV-2 Singapore, January 23-March 16, 2020. MMWR Morb Mortal Wkly Rep [Internet]. 2020 [cited 2021 Jan 16];69. Available from: https://www.cdc.gov/mmwr/volumes /69/wr/mm6914e1.htm

[4] Advice on the use of masks in the community, during home care and in healthcare settings in the context of the novel coronavirus (COVID-19) outbreak [Internet]. [cited 2021 Jan 16]. Available from: https://www.who.int/publicationsdetail-redirect/advice-on-the-use-ofmasks-in-the-community-duringhome-care-and-in-healthcaresettings-in-the-context-of-the-novelcoronavirus-(2019-ncov)-outbreak

[5] Use of facemasks during the COVID-19 pandemic - The Lancet Respiratory Medicine [Internet]. [cited 2021 Jan 16]. Available from: https://www.thelancet.com/journals/1 ancet/article/PIIS22132600(20)30352-0/fulltext

[6] Sjödin H, Wilder-Smith A, Osman S, Farooq Z, Rocklöv J. Only strict quarantine measures can curb the coronavirus disease (COVID-19) outbreak in Italy, 2020. Euro Surveill [Internet]. 2020 Apr 2 [cited 2021 Jan 16];25(13). Available from: https://www.ncbi.nlm.nih.gov/pmc/a rticles/PMC7140595/

[7] Homepage | European Centre for Disease Prevention and Control [Internet]. [cited 2021 Jan 16]. Available from: https://www.ecdc.europa.eu/en

[8] Association of Public Health Interventions With the Epidemiology of the COVID-19 Outbreak in Wuhan, China | Global Health | JAMA | JAMA Network [Internet]. [cited 2021 Jan 16]. Available from: https://jamanetwork.com/journals/ja $\mathrm{ma} /$ fullarticle/2764658

[9] WHO Director-General's opening remarks at the media briefing on COVID-19 - 11 March 2020 [Internet]. [cited 2020 Dec 18]. Available from: https://www.who.int/director- 
general/speeches/detail/who-directorgeneral-s-opening-remarks-at-themedia-briefing-on-covid-19---11march-2020

[10] Iwasaki A, Grubaugh ND. Why does Japan have so few cases of COVID-19? EMBO Mol Med [Internet]. 2020 May 8 [cited 2021 Jan 16];12(5). Available from: https://www.ncbi.nlm.nih.gov/pmc/a rticles/PMC7207161/

[11] COVID-19 National Emergency Response Center, Epidemiology \& Case Management Team, Korea Centers for Disease Control \& Prevention. Contact Transmission of COVID-19 in South Korea: Novel Investigation Techniques for Tracing Contacts. Osong Public Health and Research Perspectives. 2020 Feb;11(1):60-3.

[12] Lotfinejad N, Peters A, Pittet D. Hand hygiene and the novel coronavirus pandemic: the role of healthcare workers. Journal of Hospital Infection. 2020 Aug;105(4):776-7.

[13] Coronavirus \& COVID-19 Overview: Symptoms, Risks, Prevention, Treatment \& More [Internet]. [cited 2021 Jan 16]. Available from: https://www.webmd.com/lung/coron avirus

[14] Publishing HH. Preventing the spread of the coronavirus [Internet]. Harvard Health. [cited 2021 Jan 16]. Available from: https://www.health.harvard.edu/disea ses-and-conditions/preventing-thespread-of-the-coronavirus

[15] Khatib, M.N., S. Gaidhane, M. Khatib, M. Ahmed, A. Gaidhane, and Z.Q. Syed. "SARS-CoV and SARSCoV-2: Similar Viruses with Different Trajectories." Wutan Huatan Jisuan Jishu 16, no. 5 (2020): 544-48.
[16] Gaidhane, S., N. Khatib, Q.S. Zahiruddin, A. Gaidhane, S. Telrandhe, and P. Godhiwal. "Depression, Anxiety and Stress among the General Population in the Time of COVID-19 Lockdown: A Cross-Sectional Study Protocol." International Journal of Research in Pharmaceutical Sciences 11, no. Special Issue 1 (2020): 360-64. https://doi.org/10.26452/ijrps.v11iSP L1.2726.

[17] Nisargandha, M.A., and S. Dadaraoparwe. "Spread of Coronavirus Disease 2019 (COVID19) during the Lockdown in the Indian Population and Preventive Measures." International Journal of Research in Pharmaceutical Sciences 11, no. Special Issue 1 (2020): 32832.

https://doi.org/10.26452/ijrps.v11iSP L1.2721.

[18] Rajput, D.S. "Evolution, Ayurveda, Immunity, and Preventive Aspects for Emerging Infectious Diseases Such as COVID-19." International Journal of Research in Pharmaceutical Sciences 11, no. Special Issue 1 (2020): 86-93. https://doi.org/10.26452/ijrps.v11iSP L1.2227.

[19] Sharma, D. "Preventive Measures for COVID-19 Health Care Professionals." International Journal of Research in Pharmaceutical Sciences 11, no. Special Issue 1 (2020): 1307-12. https://doi.org/10.26452/ijrps.v11iSP L1.3626.

[20] Deshpande, A.M., and M.A. Deshpande. "Role of Rasayan Churna in Outbreak of COVID-19 as Preventive and Curative Aspect." International Journal of Research in Pharmaceutical Sciences 11, no. Special Issue 1 (2020): 1208-12. https://doi.org/10.26452/ijrps.v11iSP L1.3594. 
[21] Deshpande, M.A., and A.M. Deshpande. "Preventive Measures for COVID 19 through Dincharya and Rutucharya Mentioned in Ayurvedic Text." International Journal of Research in Pharmaceutical Sciences 11, no. Special Issue 1 (2020): 239-45. https://doi.org/10.26452/ijrps.v11iSP L1.2705.

[22] Khatod, S., A. Ikhar, P. Nikhade, and K. Khatod. "Preventive Measures for Dental Professionals during Worldwide Emergency COVID-19." International Journal of Research in Pharmaceutical Sciences 11, no. Special Issue 1 (2020): 150-53. https://doi.org/10.26452/ijrps.v11iSP L1.2294.

[23] Dhole, P.D., V.K. Lohe, R.P. Kadu, S.C. Mohod, M. Meshram, and G.A.
Thakare. "Post COVID-19 Protocol of Treatment, Radiologic Examination and Infection Control in Dentistry." International Journal of Research in Pharmaceutical Sciences 11, no. Special Issue 1 (2020): 138489.

https://doi.org/10.26452/ijrps.v11iSP L1.3664.

[24] Late, S.V., H. Keche, V.K. Chimurkar, and V. Anjankar. "Protocol for Handling and Disposal of the Dead Bodies in Covid-19." International Journal of Current Research and Review 13, no. 1 (2021): 7-9. https://doi.org/10.31782/IJCRR.2021 .13102 . 